\title{
Los modos del cine documental. Análisis de tres modelos
}

\section{The Ways of Documentary Cinema. Analysis of Three Models}

\author{
Carlos Guillermo Lloga Sanz \\ Universidad de Oriente, Santiago de Cuba \\ carloslloga@uo.edu.cu
}

\section{Resumen}

El presente trabajo es un estudio teórico que compara los modos de representación documental proporcionados por Bill Nichols, Michael Renov y John Corner. Estos paradigmas corresponden al auge de los estudios sobre el documental de inicios de los años noventa del siglo veinte y han devenido matrices prominentes a partir de las cuales se reinterpreta la estética fílmica y la historia del documental. La revisión crítica que se propone aquí incluye el análisis de algunos ejemplos puntuales del cine documental cubano producidos por el Instituto Cubano de Arte e Industria Cinematográficos (ICAIC) entre 1959 y 1991. Los tres modelos clasificatorios que se siguen identifican fondos teóricos diferentes sobre el que proyectan la imagen del documental, por esa razón, este estudio defiende la triangulación de sus cuerpos categoriales ante el examen de volúmenes significativos de documentales.

Palabras clave: documental, modalidades, estética cinematográfica, estudios sobre el documental, cine cubano.

\section{Abstract}

The present work is a theoretical study that compares the modes of documentary representation provided by Bill Nichols, Michael Renov, and John Corner. Such paradigms correspond to the increase of documentary studies from the beginnings of nineties of $20^{\text {th }}$ century. They have become prominent guides for the reinterpretation of aesthetics and history of documentary film. The critical revision proposed here includes the analysis of specific examples of Cuban documentary films produced by Cuban Institute of Art and Cinematic Industry (ICAIC) between 1959 and 1991. The three models followed identify different theoretical backgrounds over which project the image of documentary, for that reason, this study argues for the triangulation of the categories in the exam of significant volumes of documentaries.

Keywords: Documentary, modalities, cinematic aesthetic, documentary studies, Cuban cinema. 


\section{Los modos del documental. ¿Cuáles y por qué?}

La amplia literatura acerca del documental generada durante la década de los noventa favoreció una comprensión multidimensional del género. Una de las direcciones más interesantes de tal esfuerzo intelectual fue la de instituir estándares históricos, estéticos y epistémicos a partir de los cuales "dar orden" al vasto universo del documental. Varios modelos clasificatorios fueron propuestos entonces. Son puntos de vista que permiten visionar el pasado y gestionar las lecturas de su presente. En sentido general, estas taxonomías son conocidas como modalidades o modos, y persiguen segmentar el vasto ámbito de la no-ficción y agrupar los filmes en bloques de filiación distinguidos a partir de los rasgos del ejercicio retórico que despliegan. Las modalidades, como concepto, se presentan lo suficientemente holgadas como para proporcionar la sensación de adaptabilidad que caracteriza la práctica documental en sí misma. Nichols define los modos como formas básicas de agrupar los textos en relación a rasgos recurrentes o convenciones (Introduction to documentary).

La literatura que aborda los modos del documental los presenta como clasificaciones universales del género. Sin embargo, tal visión se focaliza esencialmente en una corriente central de la historia del documental mayoritariamente europeo y norteamericano. Ámbitos estos, por cierto, donde el género ha sido secundario o subalterno con respecto a la ficción. De forma tal que los modos no solo proveen ejes de entendimiento que favorecen la interpretación de las películas, sino que activan además mecanismos de legitimación de ciertas tradiciones de representación. Ello no los descarta como instrumentos útiles para el análisis de ambientes cinematográficos de otras latitudes (como el caso cubano), pero definitivamente obliga a ubicar las teorías acerca de las modalidades dentro de un marco crítico que contextualice sus presupuestos.

El auge de los estudios sobre el documental correspondientes a las décadas finales del siglo xx contribuyó a convertir a este género en un objeto relevante para la indagación científica. Los esfuerzos por descubrir en la no-ficción definiciones, características comunes, funciones y efectos, han tenido un crecimiento y aceptación notable en la comunidad científica global (Renov 1; Carroll 224; Plantinga 6; Corner, Documentary studies 13; Del Rincón 30). Ello condujo a Michael Renov (1) a declarar tempranamente que la marginación del documental como tema de investigación seria había llegado a su fin. Los esquemas de modalidades se encuentran en el núcleo mismo de esta vocación metódica, la cual, de acuerdo con David Bordwell (Poetics of cinema 11), es cualidad necesaria de la consolidación de los film studies en la academia.

En este texto se diferencian los modos de otros tipos de clasificaciones del documental como los subgéneros. La razón fundamental radica en que la literatura que aborda los géneros del documental construye sus concepciones a partir de una mixtura entre temáticas, convenciones estilísticas (narrativas y visuales) y cualidades institucionales. Ello convierte el debate de los subgéneros en un terreno entrópico donde el contenido de los filmes adquiere una posición relevante. Es decir, aunque 
un filme de la naturaleza, por ejemplo, puede abordar cualquier tópico específico o emplear cualquier artilugio para contar la historia, parece claro que la categoría favorece la promoción de ciertos asuntos y este privilegio da nombre a la categoría. Es por ello que no se toman en cuenta en este artículo clasificaciones del documental como la de Keith Beattie (2) o la de Patricia Auftherheide (56-124).

En cambio, se analizan las tipologías propuestas por Bill Nichols (Introduction 142-171), ${ }^{1}$ Michael Renov (12-36) y John Corner (The Art of Record 9-30) para la comprensión de las constantes y variaciones que cualifican el documental. ${ }^{2}$ Estas se caracterizan por estructurar las películas sobre la base de mecanismos expresivos, o sea, disposiciones textuales que determinan la apariencia del filme y sus pretendidos efectos. Sobresalen por su ahistoricidad, lo que potencia su reacomodo para el estudio de cinematografías específicas. De los tres modelos estudiados aquí, solo el de Nichols formula una voluntad evolutiva de la experiencia documental y, precisamente, tal genealogía ha sido uno de sus aspectos más criticados. ${ }^{3}$

Una oposición contundente es defendida por Stella Bruzzi (3-5), quien rebate la noción de líneas progresivas implícitas en la propuesta de Nichols. De acuerdo con Bruzzi este prototipo es construido desde un paradigma teórico cuya extrapolación al entorno histórico en términos de sucesión natural resulta inapropiada. Las múltiples fuentes que alimentan el quehacer documental, los usos del mismo a un nivel social, la naturaleza transmediática que tipifica su estado actual y la pluralidad de efectos anudados en sus engranajes comunicativos, todos actuando al unísono, impiden que ni el modelo de Nichols ni los otros dos presentados aquí puedan ser articulados de forma coherente en una historicidad lineal. Es por ello que, para evitar la imposición de "un canon central que es exclusivo y conservador" (Bruzzi 4), el presente estudio propone una triangulación de los modelos que certifique de la riqueza expresiva del género documental.

1 Es relevante señalar que Nichols llamó a su modelo subgéneros en la primera edición de Introduction to documentary (publicada en 2001), sustituyendo así el término de "modalidades de representación" empleado en Representing reality (publicado diez años antes, en 1991). En la segunda edición de Introduction to documentary (del año 2010) retoma los términos "modos", "modalidades" o incluso otros más abstractos como "prototipos".

2 No fue tomada en consideración en este análisis la propuesta de Carl Plantinga (106-119) quien nombra tres prototipos de documentales: voz formal, voz abierta y voz poética. La razón fundamental es que, como el mismo autor señala, "[...] el propósito de la tipología no es tanto categorizar como llamar la atención hacia algunas de las funciones mayores de las no-ficciones y los significados textuales por los cuales el filme ejecuta [perform] esas funciones" (106). Es necesario apuntar que la motivación principal de Plantinga era ofrecer un modelo que permitiera dar espacio a las formas poéticas y experimentales del documental, las cuales habían sido omitidas de la clasificación original de Bill Nichols en 1991. Esa falencia fue resuelta en modelos posteriores como el que se estudia aquí. Además, como se colige de la cita, a pesar de la evidente importancia del criterio de Plantinga, su marcado enfoque en las funciones del documental también es asumido por Renov, cuya clasificación ofrece una estructura más definida.

3 Nichols declara en numerosas ocasiones que los modos han de ser entendidos como recursos y no como evolución histórica per se, y apoya su reclamo en la coexistencia de sus manifestaciones. Sin embargo, la voluntad histórica es evidente, declarada explícitamente, y así ha sido reconocida desde su aparición en Representing Reality (ver Corner, Review on Nichols 415). Ciertos investigadores de prestigio en el campo, como Carl Plantinga (101), han aplaudido también la diacronía de los modos de Nichols. Ello, no obstante la negativa de su autor, actúa como legitimador de sus concepciones, al asociar su postura al discurso de la historia del cine, una retórica ya normalizada (aunque no carente de problemáticas) en la cultura occidental. 
Cada disposición referida aquí atiende la constitución del documental enfocándose en diversas áreas. El esquema de Nichols identifica recursos que han dominado el registro de la realidad. Señala cómo la combinación de estos atributos da lugar a ciertas formas organizacionales en las obras y cómo este orden responde a sistemas ideológicos. La asociación entre representación y política es cardinal en este autor. Nichols asume el documental como elemento integrante de la tradición del cine y defiende la autonomía del género al no reconocer obras en plataformas de medios diferentes. Es por ello que su diagrama encaja con facilidad en el razonamiento del fenómeno hasta los años ochenta, pero sufre en la medida en que la convergencia mediática descoloca el sentido de tradición única.

Las modalidades de Michael Renov siguen un camino diferente. Aquí se enfoca en los propósitos que movilizan a los filmes. Para Renov existen motivaciones que son universales al ejercicio documental y esos móviles son los que inducen las propiedades conformadoras de la película. Es un esquema que hace ver a los agentes gestores de las obras, pues reconocer el "para qué" se realiza un filme lleva implícito una deducción

\section{FIGURA 1}

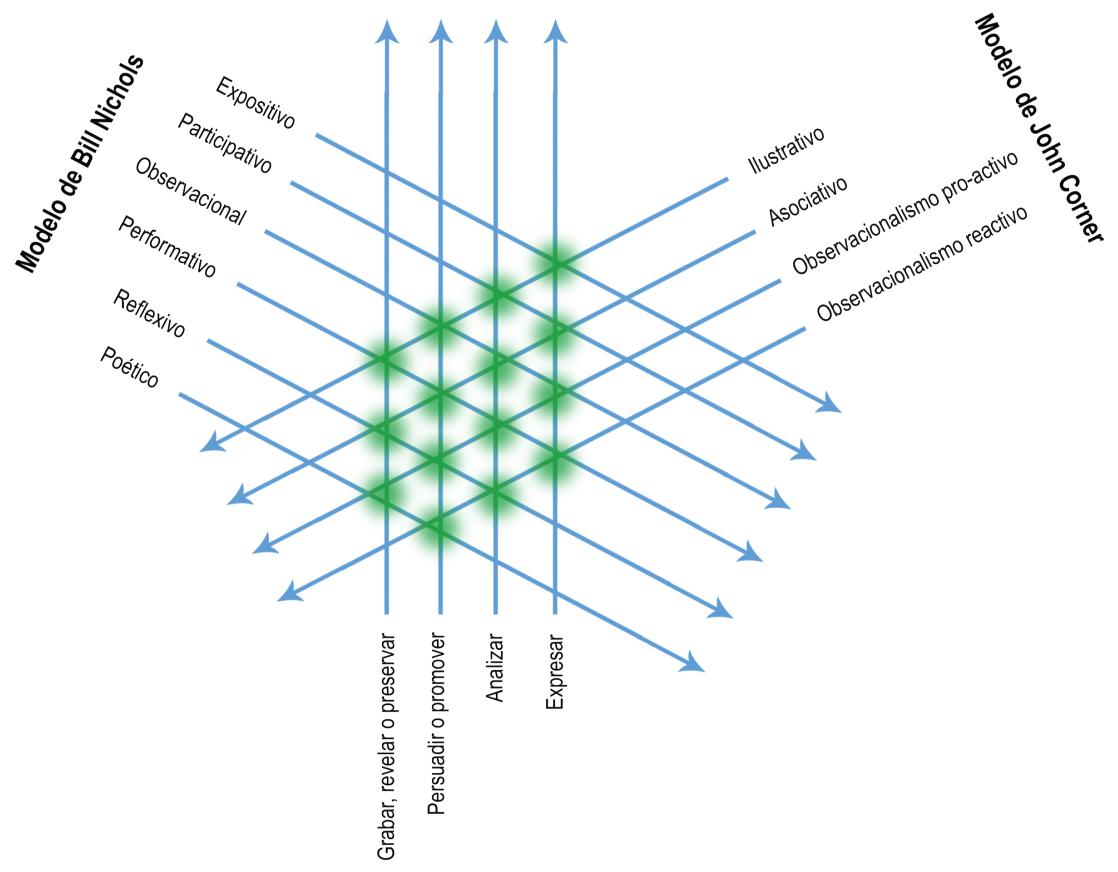

Modelo de Michael Renov

Densidad de datos ofrecida por la aplicación de diferentes clasificaciones de las modalidades del cine documental. 
de quién lo realiza y hacia quién va dirigido. No obstante, el patrón que construye Renov tiene una perspectiva excesivamente general, que hace difícil asociar recursos específicos consonantes con los modos. De ahí que su entendimiento con respecto a filmes puntuales puede que no sea muy efectivo.

La clasificación de John Corner ofrece nuevas posibilidades. Sus modos atienden a la manera en que se organiza la comunicación en los textos audiovisuales. Corner ofrece una distinción más concentrada en el tipo de interacción que el filme ofrece sobre el mundo. En esta codificación hay una intención de apuntar hacia cuál es el soporte comunicativo que soporta la premisa del documental: si es la observación (intervención visual de la realidad), si es el ámbito sonoro (preponderancia del discurso hablado) o si yace en la combinación multisensorial de los contenidos audiovisuales. La ordenación de Corner es aplicable a la no-ficción, traspasando las convenciones del documental y permitiendo una mayor proximidad con otras formas retóricas como el reportaje noticioso, la video experimentación, etc. Las restricciones principales de esta categorización son los inconvenientes que surgen al intentar establecer diacronías en las prácticas audiovisuales o cánones de representación.

Las definiciones no han de verse como fronteras exclusivas. Ningún filme es del todo expositivo o completamente participativo, por ejemplo. Las clasificaciones genéricas designan configuraciones discursivas que revelan tanto estrategias comunicativas (narrativas y visuales) como aplicaciones y usos concretos del documental en tanto práctica social. Esa fluidez que porta el género, de acuerdo con Nichols, no figura un fallo o motivo de lamentación, sino demostración de su vitalidad, riqueza y adaptabilidad como forma artística (Introduction 142). Es aquel rasgo dominante el que determina la clasificación y descubre el poder arcóntico tras el registro de signaturas que da orden a cualquier reservorio (Derrida).

Los modelos aplicados aquí responden a un abanico teórico diferenciado. Aun así, son contemporáneos, de modo que existe entre ellos una correlación histórica con respecto a la evolución del documental, así como un maridaje teórico entre sus autores, quienes no solo se citan mutuamente, sino que asumen posturas coherentes o diferenciadas a partir de un reconocimiento epistemológico consciente. El objetivo del presente texto es ofrecer primariamente un estudio teórico, dada la pluralidad enmarañada de voces involucradas en la discusión contemporánea sobre el documental y sus modos.

Asimismo, se analizan particularidades que los distintos modos han experimentado en la documentalística cubana producida por el Instituto Cubano de Arte e Industria Cinematográficas (ICAIC) o asociada de alguna manera al mismo, como el caso del filme PM (1961, Sabá Cabrera Infante y Orlando Jiménez Leal). Tal inclusión persigue una misión de sondeo, de diagnóstico inicial. El examen no solo incluye filmes que resultan paradigmáticos de ciertos modelos, sino que señala además casos atípicos o momentos de confrontación donde el debate cubano acerca de las definiciones estéticas tuvo en los modos la razón de la discordia. 
Se comprende, no obstante, que la exploración de la genealogía profunda de las modalidades en la historia del cine cubano es una tarea que sobrepasa el alcance y objetivos de este estudio. Las referencias concretas a documentales cumplen una función ilustrativa, por lo que en los análisis no se sigue una lógica diacrónica sino argumentativa. Los ejemplos escogidos corresponden al periodo que va entre 1959 (fecha de fundación del ICAIC) hasta 1991, cuando la crisis económica hizo caer drásticamente la producción documental del instituto. A partir del examen de las modalidades, este estudio ofrece un marco teórico que permite pensar el documental cubano más allá de su cualidad como cine nacional (modelo teórico dominante) e incorpora nuevas posibilidades de examen estético propias de la tradición del género documental.

\section{El modelo de Bill Nichols}

Bill Nichols provee la clasificación de documental más reconocida. Como afirma Stella Bruzzi, los posicionamientos de Nichols han sido convertidos en discurso preponderante dentro de los estudios sobre documental. Bruzzi es muy clara al respecto: "En algunos cursos de pre-grado los modos de Nichols son atribuidos como si fueran no una forma de mirar la historia y producción del documental, sino la forma de entenderlo" (3). Y más adelante asegura que: "El resultado - ya sea consciente o no- de haber impuesto este árbol familiar' en la historia del documental es la creación de un canon central de filmes que es exclusivo y conservador" (4). También ha sido así en Cuba, donde este autor es, definitivamente, la voz más empleada.

Es destacable, no obstante, que las categorías que propone Nichols para el documental han evolucionado desde que las presentara en Representing Reality. Issues and Concepts on Documentary. En este primer momento fueron debatidos cuatro modos de representación: expositivo, observación, interactivo y reflexivo. Luego, en Introduction to Documentary $1^{\text {st }}$ ed., Nichols formula dos prototipos más, a saber, el poético y el performativo. La modalidad poética fue una ausencia significativa del libro de Nichols de 1991 y señalada efectivamente por otros investigadores como Plantinga (103). Ya Barbash y Taylor en su clásico Cross-cultural Filmmaking. A Handbook for Making Documentary and Ethnographic Videos, publicado en 1997, habían planteado una clasificación que se inspiraba en la esbozada por Nichols (aunque excesivamente simplificada) e incorporaban la forma poética como una opción relevante dentro del documental. En el presente artículo se examinan las seis categorías de Introduction to Documentary $2^{\text {nd }} e d$. para clasificar modélicamente el documental.

Lo que sí es perceptible, en atención al llamado realizado por Bruzzi, es que a pesar del reconocimiento de las concepciones de Nichols, sus criterios no corresponden a axiomas universales, sino que actúan en circunstancias históricas específicas que es necesario comprender y analizar. Ello no solo porque son criterios que cuentan con una evolución en sí mismos dentro de la obra total del propio autor, como se ha señalado, 
sino porque su recepción global está marcada por dinámicas específicas de circulación. La publicación en español de La representación de la realidad. Cuestiones y conceptos sobre el documental ocurre en 1997, justamente cuando el propio autor había ya modificado su clasificación por modalidades. De esa manera, la publicación de Paidós nació desfasada y, en consecuencia, también su recepción amplia en los países de Iberoamérica. Situaciones de esta naturaleza han marcado el desarrollo de los film studies en Cuba, y aún hoy, esta edición de 1997 es el texto de Nichols más citado en la Isla. ${ }^{4}$

Nichols (Introduction 154) afirma la prevalencia del modo expositivo en el documental aun y cuando reconoce que los filmes pueden combinar las características de varias modalidades. Se basa en que el documental expositivo da prioridad a la palabra hablada y plantea una perspectiva proveniente de una sola fuente unificadora. Es un decir "sobre el mundo" que pone en acción métodos de convencimiento basados en la legitimidad de aquel que cuenta. Es común el uso de la voz en off (voz de Dios) para guiar la trama del filme y no pierde el control jamás de la circunstancia del mundo histórico que es abordada. Debido a ese sentido dominante, paternalista en ocasiones, el modo tiene una marcada tendencia al didactismo.

El documental participativo tiene su fundamento en el encuentro del realizador con el sujeto-objeto del filme. Supone un involucramiento del individuo filmado con la práctica de su representación. Asimismo, inviste a un personaje específico con cualidades del autor-persona (aquel-que-filma) que interactúa con una realidad determinada. Ello provoca una sensación de inmersión en el mundo histórico y vigoriza la impresión de veracidad de la obra. De ahí que esta modalidad ancla a un sujeto (narrador-implícito) en un lugar y tiempo específico, en un yo-estuve-allí que certifica su función de contador de la historia.

Nichols asevera que el surgimiento de esta modalidad corresponde a los años sesenta, favorecido por el aligeramiento de las cámaras y la incorporación de sonido sincrónico. En tanto prototipo de filme, este modo funciona como contrapeso del documental de observación, con el que comparte no solo la causa de origen en la facilidad tecnológica sino que, además, ofrece una sensación de espontaneidad basada en las situaciones reales. Por tanto, ambas modalidades asumen la problemática de representación/realidad como núcleo de sus acercamientos al mundo histórico. La oposición cinema-verité y cine directo es puesta en acción aquí. La interacción de los sujetos con el proceso de construcción mediática es el eje de la modalidad participativa.

De igual manera, Nichols anota varias diferencias de esta forma con respecto a otros modelos. Además, al incluir al realizador como personaje comprende la reflexividad como elemento característico de esta tipología. La participación constituye un

4 Véase por ejemplo 33 Ensayos sobre cine de Edgar Soberón o La mirada bajo asedio. El documental reflexivo cubano de Dean Luis Reyes. Ambos libros han tenido una marca significativa en los estudios sobre el documental cubano. Los dos emplearon como fuente analítica casi exclusivamente el texto de Nichols y prestan especial atención a su clasificación modélica de acuerdo con su publicación por Paidós. 
posicionamiento ético al proponer un acercamiento visible entre aquel-que-filma y aquel filmado, y al asumir la realización misma de un texto audiovisual como principio negociado por ambas instancias.

No obstante, el fragmento de Nichols también esclarece que la intervención del realizador en el mundo histórico no es otra cosa que una táctica narrativa y deriva, en definitiva, en un intercambio regulado. Por profunda y evidente que sea la acción profílmica, la elaboración de texto y la responsabilidad del mismo corresponde solo al realizador, por lo que su intervención se efectúa con un carácter de personaje. La autenticidad de la premisa, aunque adquiere con la participación una de sus posibilidades más verosímiles, se sostiene en definitiva en una postura ética y en la convención social que concede al documental ser un discurso verídico sobre el mundo histórico. ${ }^{5}$

La adquisición por el ICAIC, en 1967, de un grupo de cámaras con sonido incorporado ${ }^{6}$ fue el espaldarazo tecnológico que permitió el surgimiento del documental participativo en Cuba. La capacidad de escuchar directamente al personaje multiplicó la capacidad comunicativa de los filmes de ese periodo, cuya narración era impulsada por un excelso trabajo de fotografía y montaje, pero, también, el uso extensivo de la voz en off, la música incidental y los intertítulos.

Un filme pionero en la cinematografía cubana generada por el ICAIC que pone en acción el modo participativo es el filme En la otra isla, producido en 1968 y dirigido por Sara Gómez. Jorge Luis Sánchez $(92,176)$ asegura que este filme es heredero de las enseñanzas del danés Theodor Christensen, quien trabajó en ICAIC a comienzos de los sesenta y trasmitió lo que llamó "cine encuesta". En la otra isla es realizado en un campamento donde a inicios de la revolución fueron ubicadas personas que sufrían los efectos de problemáticas sociales para su "re-educación" en la nueva sociedad que se creaba. Allí fueron recluidos además individuos disonantes de una sociedad modélica, como religiosos y homosexuales.

Sara Gómez realiza su película a partir de las entrevistas a varias de estas personas, al igual que a instructores del campamento. Apenas hace uso de la música no-diegética, lo que resulta una cualidad sobresaliente debido a que es un recurso que experimenta un uso extensivo en el cine documental cubano de la etapa. La realizadora sale todo el tiempo en pantalla. La fotografía aparenta descuido y no se concentra más que en la interacción humana. Contrario a la usanza cubana del momento, En la otra isla no muestra una gran preocupación por el montaje. Es un filme atípico en muchos sentidos que van desde lo temático hasta lo estético; constituye uno de los primeros experimentos de documental participativo en la historia del cine cubano. Por eso, el

5 Varias formas de ficción contemporáneas asumen la retórica participativa propia de los medios contemporáneos para construir sus propuestas estéticas. Filmes como The Blair Witch Project (1999, Daniel Myrick y Eduardo Sánchez), The Wild Blue Yonder (2005, Werner Herzog) o What we do in the shadows (2014, Jermaine Clement y Taika Waititi) son algunos ejemplos que asumen la estética documental.

6 El dato es ofrecido por Luciano Castillo, director de la Cinemateca de Cuba, en conferencia magistral ofrecida en la Universidad de Oriente, Santiago de Cuba, en el mes de marzo de 2019. 
crítico Juan Antonio García Borrero (179) llama al cine de Sara Gómez una excepción estilística y conceptual. La recepción oficial de sus filmes es difusa y ha sufrido del ostracismo durante décadas. Aunque hoy es celebrada como una de las figuras cimeras del documental cubano, la atención que dio a personajes subalternos e inadaptados la mantuvo en los márgenes de lo más reconocido del documental cubano de esa época.

Nichols (Introduction 160) declara que el surgimiento de la modalidad de observación tiene dos pilares fundamentales. Uno de tipo tecnológico, la aparición del sonido sincrónico y el aligeramiento de las cámaras; y otro de carácter filosófico, a saber, la neutralidad aparente promovida por el auge de la descripción basada en la observación de la sociología de finales de los cincuenta, así como la fascinación por la vida diaria. Este autor asume el modo observacional a partir de los problemas éticos que conlleva la pretensión de no-intrusión en los eventos de la vida real. El origen de la idea central de la modalidad radica en los movimientos de cine directo de los sesenta, aunque también analiza filmes realizados en otras épocas.

Sin embargo, este estudio defiende que la identificación del documental de observación resulta particularmente problemática si se tiene en cuenta que la práctica cinematográfica en general se sostiene en la observación como esencia de su ser. Todas las modalidades incluyen diferentes perspectivas y actitudes de observación. Por tanto, determinar el grado de primacía en la presentación de la premisa de cada película puede devenir controversial. Un ejemplo de esto es el documental etnográfico, el cual se asienta en la expectación del mundo histórico. Aun así, la variedad de narrativas puestas en acción dentro del subgénero ofrece espacio para una mixtura intensa de las modalidades tal y como las entiende Nichols.

Un clásico del cine antropológico como Dead Birds (1963, Robert Gardner), por ejemplo, es el resultado de años de investigación y de observación de la cultura de los Dani, en Papúa Nueva Guinea. El filme, no obstante, cuenta con un narrador en off, omnisapiente y omnipresente, que conduce no solo la evolución de los eventos, sino que además es imprescindible para la comprensión de los mismos. Este elemento hace que Dead Birds haga colisionar las modalidades expositivas y de observación, a pesar de que esta última condiciona la estética del filme (sin entrevistas, sin música suplementaria o efectos sonoros, ${ }^{7}$ sin intertítulos, con preferencia a la toma larga, etcétera).

Así, lo que Nichols llama modalidad de observación no es una noción universal. Es más bien la descripción de una forma de realización documental específica notoria en los años sesenta e inserta en la tradición cinematográfica europea y norteamericana. Su existencia en circuitos alternativos al mainstream global (como Cuba), adquiere características peculiares marcadas por las dinámicas propias del desarrollo del fenómeno cinematográfico en cada espacio.

7 Un análisis más detallado del uso del sonido en Dead Birds aparece en la crítica de Jay Ruby, "Robert Gardner and the Anthropological Cinema" publicada en Picturing Culture. Explorations of Film and Anthropology (Ruby 95-111). 
En Cuba, este prototipo no ha tenido mucha presencia, debido en parte al debate provocado por el filme PM (1961, Sabá Cabrera Infante y Orlando Jiménez Leal). ${ }^{8}$ Como parte de la voluntad de experimentación que tipificó la primera década de la Revolución, el documental exploró varias maneras de enfrentarse a la realidad. El valor atribuido entonces al cine documental fue esencialmente político, como agente movilizador de masas, aunque pronto adquirió una progresiva estetización que supuso la temprana revaloración del género como obra de arte (Lloga y Silveira 111). PM fue una de las obras que participó de esa actualización estética del documental en Cuba, pues constituyó una propuesta pionera de cine directo en la isla. Las circunstancias políticas que circundaron el filme produjeron su censura y su elevación a un estadio mítico como fenómeno definitorio de la política cultural revolucionaria.

Pero además de las discusiones que generó, concernientes en su mayoría a la libertad de expresión y al rol del intelectual en un país en revolución, ${ }^{9}$ también se sucedió una significativa polémica alrededor del cine directo como corriente cinematográfica que involucró, por un lado, a Néstor Almendros y, por el otro, a directivos y cineastas del ICAIC como Alfredo Guevara y Tomás Gutiérrez Alea. ${ }^{10}$ Almendros escribió de manera positiva acerca de $P M$ en una crítica publicada en la revista Bohemia, en mayo de 1961. Encomiaba su sencillez y espontaneidad, pero sobre todo, su definición consciente hacia la exploración de una estética en auge en el mundo y novedosa en Cuba. ${ }^{11}$ Almendros señala también que, a pesar del uso de la "cámara-bisturí", el propósito de registro no niega las cualidades artísticas y apunta la gestión de los realizadores como organizadores de la realidad filmada, responsables de una "transfiguración poética de hechos que son comunes" (11). Gutiérrez Alea, por su parte, acentúa la propiedad de "realidad manipulada" de cualquier ejercicio de representación. A partir de ello, desacredita no las cualidades formales del cine directo, sino la pretendida ingenuidad política implícita en un estilo de no-intervención. Tal fundamento es desarrollado por este cineasta con mayor profundidad en su Dialéctica del espectador, publicado inicialmente en 1978, pero está en el centro de su postura ante la censura de PM en 1961:

Ahora, yo creo que ha quedado bastante claro [...], que no se trata de una película contrarrevolucionaria, pero que sí se trata de una película que, al tocar un aspecto de la realidad, no lo toca en una forma debida y, por lo tanto, dice una mentira de la manera más hipócrita que se puede decir, que es ocultando una parte de la verdad. Cuando no se analiza el punto de la realidad, estamos exponiendo [la] nuestra, o [se] está exponiendo al margen de lo que es Cuba

8 Jiménez Leal ha expresado que la realización de $P M$ estuvo inspirada en varios cortos realizados con la estética del free cinema, y en particular por el clásico Primary de los hermanos Maysles (Jiménez y Zayas 144).

9 Para un recuento de algunas de las problemáticas intensamente debatidas en el ambiente cultural de la primera década de la Revolución, ver Polémicas culturales de los sesenta, de Graziella Pogolotti.

10 Un análisis exhaustivo de las confrontaciones ideológicas alrededor de PM puede ser encontrado en el capítulo 6 "The Coming of Socialism" en Cuban Cinema de Michael Chanan.

11 El propio Almendros realiza ese mismo año de 1961 Un día en la playa, otro corto documental de estilo directo. 
en el año 1961, Año de la Educación, y que francamente no corresponde a la realidad de Cuba, aunque eso sea una parte de la película (Discusiones 173).

La cita demuestra, como plantea Michael Chanan, que desde el ICAIC "la experimentación formal era perfectamente deseable, pero no la preocupación formalista” (131). Así, el cine cubano posrevolucionario dio la espalda al observacionalismo y con ello a lo que Nöel Carroll llama la mayor influencia en la manera en que la no-ficción es conceptualizada (224). A partir de entonces, el documental del ICAIC apostó por el trabajo con la edición y los principios del montaje intelectual inspirados en los fundamentos de la vanguardia soviética, así como con la música y los efectos sonoros no-diegéticos. Los resultados de esta labor produjeron las obras más notables de la década y su reconocimiento internacional. El éxito del documental del ICAIC de los sesenta constituye una paradoja estética ya que sus propuestas daban la espalda a aquellos principios que movilizaban la documentalística a escala global. ${ }^{12}$

El apogeo del documental performativo a escala global corresponde a los años ochenta y noventa. Para Nichols, el advenimiento de esta modalidad tiene raíces políticas. Las explicaciones que ofrece este autor sobre la modalidad son francamente confusas, debido a que considera que el filme performativo no tiene cualidades retóricas definitorias, sino que comparte características con el resto. Igualmente, enfatiza en la cercanía con el filme poético.

Nichols no ofrece elementos distintivos del texto audiovisual que resulten identificables. Stella Bruzzi, por otra parte, en New Documentary $2^{\text {nd }}$ Edition, ofrece una mejor identificación de este tipo de películas. Para ella los documentales son performativos en la medida en que funcionan como una expresión que simultáneamente describe y ejecuta una acción (186). La autora declara que hay dos formas de descripción de un filme documental como performativo: una, muestran sujetos performativos, los cuales son marcadamente estilizados; y dos, aquellos que son inherentemente performativos y muestran la presencia intrusiva del realizador (187). ${ }^{13}$ El documental performativo es, entre los tipos del modelo de Nichols, aquel que desarrolla mayor cantidad de recursos de ficcionalización. Ya sea desde el empleo de actores para la reconstrucción de sucesos del pasado o el registro de acciones que constituyen en sí mismas puestas en escena para un público, el filme performativo asume la puesta en escena como base de su premisa.

Esta fue una modalidad que caracterizó la documentalística del ICAIC de los años ochenta. En esta época hubo una intensa exploración por parte de la industria cubana

12 La observación en el documental está presente en las obras de autores como Nicolás Guillén Landrián en su primera etapa (1963-1966), con películas como En un barrio viejo (1963). Aunque es menester aclarar que nunca siguió (ni Guillén Landrián ni otros) los principios del cine directo tal y como los propone Nichols.

13 A pesar de que la descripción de Bruzzi es mucho más clara que aquella que ofrece Nichols, nótese como esta segunda forma de performatividad (aquella que involucra la presencia intrusiva del realizador) consiste en sí misma en una forma de reflexividad, por lo que la fusión entre modalidades parece inevitable. 
de las fronteras entre ficción y documental. Aunque la sinergia entre ambos géneros fue habitual desde siempre en el ambiente cinematográfico cubano, la performatividad fue uno de los rasgos novedosos asumidos por la generación de documentalistas del Instituto de Cine en los ochenta (Tamayo).

Tamayo plantea que entre las causas de tal promoción se encuentran el desempeño de los realizadores en la ficción y el documental al mismo tiempo. Varios de los cineastas que protagonizaron el cambio generacional dado en el ICAIC por entonces produjeron obras documentales en las cuales la manipulación de la puesta en escena (escenografía e iluminación) y las dramatizaciones se convirtieron en recursos habituales. La intervención en la realidad con un fin cinematográfico es rasgo central en filmes como Crónica de una infamia (1982, Irene Kuchilán), No es tiempo de cigüeñas (1987, Mario Crespo) y, en un caso extremo de indefinición de fronteras entre géneros, La espera (1983, Orlando Rojas).

Por otra parte, el documental poético rechaza la sensación de lógica espacial y temporal. En su lugar, "explora asociaciones y patrones que involucran ritmos temporales y yuxtaposiciones espaciales" (Nichols, Introduction 162). En tanto modo de documental, potencia la necesidad de expresión a la transmisión de una idea concreta, por lo que comúnmente genera una visión altamente estetizada de la realidad. Se considera, por tanto, la proposición de una sensación individual (y por ende autoral) más que la representación fiel de acontecimientos del mundo histórico. Aquí, el elemento subjetivo de la percepción individual recibe un alto grado de relevancia. Estas obras se conectan con el espectador en un sentido emotivo. Como forma retórica se encuentra presente desde el origen mismo del género documental. Nichols insiste en el vínculo epistémico del documental poético con el modernismo vanguardista a partir de asumir la imagen de la realidad "en términos de una serie de fragmentos, impresiones subjetivas, actos incoherentes, y asociaciones libres" (164).

La clasificación de Nichols acerca del documental reflexivo es especialmente controversial por la ausencia de elementos definitorios. Hay una evidente evolución de su concepción desde La representación de la realidad... hasta Introduction to documentary. En el primero, el modo es explicado de una forma muy oscura en la que salta de una modalidad a otra y resume la tipología prácticamente por lo que no es (“a diferencia del modo observacional, expositivo o participativo..."). En el segundo su concepción es mucho más clara y resumida. La idea de Nichols de documental reflexivo es que, mientras que la mayor parte de la producción documental se ocupa de hablar acerca del mundo histórico, esta modalidad aborda la cuestión de cómo se habla acerca del mundo histórico. Es así que el foco de atención se desplaza hacia la relación entre el realizador y el espectador (Introduction to documentary 194). Para Nichols la reflexividad constituye un acto cuestionador y apunta que la mayoría de los filmes reflexivos se refieren al proceso mismo de realización de la película.

La complejidad de la reflexividad en el documental se agudiza puesto que se tiende a equivocar el "sujeto" con el "individuo". Para Bordwell ("Contemporary film" 
15) el sujeto es "el terreno que hace posible el significado, la diferencia y el placer" mientras que el individuo es la entidad capaz de portar la condición de sujeto. También afirma que la desorientación que trastoca ambos conceptos ha sido común en los film studies donde se religan indistintamente el sujeto "concebido como el terreno de conocimiento o experiencia filosófico/psicoanalítico/ideológico y el sujeto concebido como aquel que sabe o experimenta — autor, personaje, analista, teórico, o cualquier agente personificado-" (“Contemporary film” 15).

La manera en que Nichols asume la reflexividad aprovecha al máximo la ambigüedad de significados que tipifica el término mismo. Mientras la reflexión es comúnmente entendida como reflejo, tanto por la semiótica del cine (Metz) como por la antropología, Nichols juega con la vaguedad del término y en ocasiones también entiende la reflexión como acto de reflexionar, es decir, la ejecución de un pensar. De esta manera, psicologiza el concepto y otorga cualidades humanas (solo los humanos tienen la capacidad de reflexionar) a un objeto, el filme, como si la película pensara o como si de alguna forma mágica pudiésemos saber lo que piensa su autor. ${ }^{14}$ Así, en la medida en que Nichols profundiza en los análisis de los filmes se produce una simbiosis en la que se confunde con frecuencia el autor implícito del filme (la estrategia discursiva que despliega la obra) y autor persona (el hombre de carne y hueso responsable por la vida social del filme). ${ }^{15}$

Ciertamente, el filme reflexivo constituye un espacio de desafíos de convenciones. Las películas cubiertas por esta tipología generalmente ofrecen también una pléyade de características coincidentes con otros modos, de ahí que su identificación resulte compleja. Este estudio coincide con Nichols en que el modo reflexivo se halla siempre subrepresentado. Ello es consecuente con la dificultad de encontrar filmes donde la construcción reflexiva constituya cualidad dominante.

El esquema de Nichols, versátil y enmarañado, permite la identificación de las expresiones estéticas más relevantes de la historia del género. Su ejecución conjuga el registro de marcas visibles en cada obra en un discurso que trasciende la especificidad de la práctica local para descubrir una dimensión histórica, un esquema representacional que aspira a ser absoluto para el género documental.

14 La forma en que Nichols construye su esquema es problemática. Aunque está diseñada para clasificar documentales de acuerdo con su retórica (filmes, por tanto, textos), en varias ocasiones se utilizan justificaciones correspondientes al accionar de individuos (ente no-textual). Ello es particularmente común en el estudio de la modalidad reflexiva. Nótese el uso de frases como "negotiation between the filmmaker and the viewer" (Introduction to Documentary 194), donde el proceso de interpretación del texto audiovisual es entendido como relación física entre individuos reales.

15 Esta confusión deliberada de la reflexión entre reflejo y cavilación ha evolucionado en la literatura de Nichols. En $L a$ representación de la realidad... era imposible distinguir entre una forma y otra. Para Introduction to Documentary $2^{\text {nd }}$ Edition, ya hay un evidente privilegio del análisis de la construcción textual, aunque las referencias psicologizantes permean todo el texto. 


\section{El modelo de Michael Renov}

Las modalidades del cine documental construidas por Michael Renov son presentadas en "Towards a Poetics of Documentary". Renov proyecta el análisis del fenómeno fílmico en un marco teórico mucho más amplio que los film studies. Para Renov, el documental es una práctica de construcción textual y, en consecuencia, su exploración asume un enfoque humanista con una firme influencia de los estudios literarios. El autor sostiene su estudio a partir de la condición periférica del documental dentro de la creación fílmica y de la no sistematicidad de los estudios sobre el mismo en comparación a la ficción. De ahí que su ensayo tenga no solo un carácter especulativo, como su propio autor señala (Renov 13), sino un aura fundacional, un intento de formar racionalidades.

Renov considera pertinente la relación entre la actitud indagatoria de la poética y aquella provista por el documental. Su justificación ante tal razonamiento es dada a partir de la posición ambigua ocupada por ambas instancias de la cultura en los límites de la ciencia y la estética, de la "verdad y la belleza" (13). La noción de poética admitida por Renov consiste en el estudio de la composición, función y efectos del texto audiovisual. La necesidad que impulsó la asociación entre poética y documental fue la ausencia de un marco de problemáticas teóricas que indiquen espacios relativamente estables de discusión. De ahí la insistencia de Renov en el "relativo empobrecimiento de una cultura de cine documental" (20), muy a pesar de la riqueza infinita del campo de no-ficción. Ello fue la ganancia principal del boom de los estudios sobre el cine documental en los noventa en el ámbito académico anglosajón: el establecimiento de espacios de debate y la proyección de actitudes teóricas inteligibles para afrontarlos.

En consecuencia, Renov plantea cuatro tendencias o "funciones retórico/estéticas" (21) del cine documental: Grabar, revelar o preservar; persuadir o promover; analizar o interrogar y, finalmente, expresar. Como es apreciable, no obstante la insistencia en el enfoque comprensivo que promueve el estudio de la poética de cualquier fenómeno textual, la disposición propuesta aquí se concentra únicamente en la motivación central que moviliza el filme. La terminología con que Renov describe su propuesta de clasificación sobresale por su lucidez. Hay diferencias sustanciales entre este modelo y aquel de Nichols. Para el último, los modos son como las caras de un poliedro, diferentes formas de ser de un mismo fenómeno y, por tanto, ejecuta su taxonomía sobre la base de identificación de recursos dominantes en las obras. Para el primero, en cambio, las clases apuntan a la identificación de los efectos propuestos por el texto audiovisual, señalan las tendencias de uso que asume el documental en la cultura, y que corresponden tanto a una voluntad de acción individual como a proyectos modernos de empleo del material de no-ficción. Es por ello que Renov llama a sus funciones "modalidades de deseo, impulsos que alimentan el discurso documental" (22).

Las categorías sobre las que Renov concibe el documental se desentienden de tradiciones cinematográficas específicas, lo que las convierte en herramienta 
dúctil para su aplicación en cualquier ambiente cinematográfico. Ello luce como una clara fortaleza. La polivalencia que establecen es fundada en la concepción de que el documental es una forma textual inserta en un entramado de otras formas textuales, coyuntura en la cual el filme de no-ficción tiene una posición definida. Podría argumentarse, no obstante, que la ordenación establecida por Renov no ofrece solución para el análisis estilístico de las obras, puesto que no asocia técnicas o procedimientos específicos asociados a las modalidades. Esta voluntad de reconocimiento de técnicas y tácticas textuales, que puede resultar en ocasiones "predominantemente descriptiva" (Bordwell, Poetics of Cinema 13), constituye elemento central en los estudios de poética, los cuales se ubican, como el propio Renov señala, en la dicotomía arte/ciencia.

La clase grabar, revelar o preservar es descrita como el aliento básico que moviliza la acción cinematográfica. Responde a la relación de similitud visual de la imagen fotográfica y su referente en el mundo histórico. Bajo este rubro se agrupan aquellas películas cuya misión esencial es dejar constancia del suceso profílmico evaluado. El modo engloba directamente la relación enrevesada entre realidad-representación que le es propia al documental. Describe, igualmente, el impulso iniciático del cinematógrafo en 1895, la evolución de los actualités y, luego, del discurso natural de los reportes de noticias hasta la contemporaneidad.

En esta modalidad, la obra es asumida como testigo de una circunstancia. Es por ello que no se trata de la compilación de imágenes que realiza una cámara solo al presionar record (memoire involuntaire), sino del despliegue de una forma discursiva que funciona como instancia probatoria no de la existencia del acontecimiento filmado, sino del encuentro de aquel-que-filma con aquel-filmado. Este modo constituye una declaración explícita del yo-estuve-ahí. El "revivir" el momento a través de la visualización del filme es solo el nomen que recibe el acto de llevar la experiencia real al ámbito de la representación. En este plano, entonces, la casualidad, la coincidencia, son solo estrategias retóricas.

Asimismo, algunas formas tradicionales del quehacer documental parecen caber perfectamente bajo el dominio de esta modalidad. El filme etnográfico no solo es una de ellas, sino que, además, es una de las que explora varias de sus posibilidades. En primer lugar, el registro cinematográfico de eventos culturales específicos es su motivación fundamental. En tanto subgénero (Aufderheide), el documental etnográfico pretende una sumisión hacia lo mostrado y declara con énfasis su carácter de referente. La acción observacional, la toma larga y la mínima intervención son algunas de sus características principales. Desde las filmaciones de Félix-Louis Regnault y Alfred Cort Haddon, hasta las producciones más contemporáneas, la voluntad de preservación de prácticas culturales permea la producción con fin etnográfico.

En segundo lugar, el asumir la observación a través de la cámara como acto revelador también es cualidad propia del cine etnográfico. Jean Rouch nombra cinétrance a los efectos producidos en el encuentro entre realizador y sujeto filmado. En 
esta circunstancia, Rouch llama la atención acerca de la toma de consciencia por el sujeto filmado de la especificidad cultural que lo identifica. El evento profílmico se convierte pues en coyuntura performada para ser recogida por el aparato cinematográfico y la actividad fílmica, por su parte, en ejercicio iluminador de la sinrazón simbólica que aspira a descubrir.

Finalmente, en la explicación de la modalidad, Renov asevera que: "El documental ha sido mayormente motivado por el deseo de explotar el poder revelatorio de la cámara, un impulso solo rara vez acompañado con un reconocimiento del proceso a través del cual lo real es transfigurado" (25). Con esta sentencia, Renov presenta una crítica no solo al reclamo de veracidad propio del cine documental, sino, y sobre todo, a la coyuntura civilizatoria que ha asumido la semejanza de percepción visual entre la imagen fotográfica y el mundo histórico como instancias análogas de la experiencia humana. La apreciación de Renov coincide con las discusiones sobre la reflexividad sucedidas en la antropología en las últimas décadas del siglo xx. El clásico Writing Culture (Clifford y Marcus) es piedra angular de dichos debates. También la antropología visual los asumió como necesidad epistémica. Sin embargo, la insistencia de Renov no solo es consonante con el universo teórico de la antropología en fechas similares, sino que ha encontrado eco en otras investigaciones en etapas posteriores (Ruby 151-152).

La no-ficción producida por el ICAIC hizo reposar el potencial de registro fundamentalmente en la gestión del Noticiero ICAIC Latinoamericano. ${ }^{16} \mathrm{El}$ mismo era concebido a la manera de los actualités y se transmitió hasta su cierre en 1991 en las salas de cine antes de comenzar cualquier función cinematográfica. Las creaciones del noticiero eran profundamente variadas y se caracterizaban por el dinamismo de su montaje. La gestión de su director, Santiago Álvarez, es decisiva en este aspecto. La necesidad de construir la imagen mediática de la Revolución a inicios de los años sesenta hizo que la modalidad grabar, revelar o preservar fuera prioridad en el seguimiento de los convulsos acontecimientos relacionados con el fenómeno social. Luego de la década del setenta, en la misma medida en que la televisión fue asumiendo el papel principal como fuente de información inmediata, las producciones del Noticiero experimentaron otras funciones que sugieren una voluntad de mayor proactividad con respecto a la realidad, como los reportajes de investigación, por ejemplo.

La segunda de las modalidades propuestas por Michael Renov es persuadir o promover. Con ella se pretende abarcar la voluntad movilizadora que le ha sido

16 El Noticiero surge en 1960 y cierra en 1991 con el inicio de la crisis económica conocida como "Periodo especial en tiempos de paz". La política de formación de realizadores del instituto de cine comprendía que los cineastas debían comenzar por trabajar en el noticiero, luego pasaban a la sección de documentales y, finalmente, llegaban a producir ficción. Esta dinámica provocó no solo el fluir de autores por los distintos géneros, sino un reconocimiento del Noticiero icaic Latinoamericano como resorte principal de la escuela cubana de cine documental. En la actualidad, las ediciones del noticiero son reconocidas dentro del programa Memoria del Mundo (MoW) de la unEsco. 
otorgada al cine documental. Su principio se basa en el axioma de que el documental tiene la capacidad de influir en el mundo histórico y se extiende más allá del documental para incluir las formas de no-ficción. Renov insiste en el dinamismo de sus clases y construye interconexiones entre las categorías.

El modo persuadir o promover se apoya en el de grabar, revelar o preservar; y se constituye en una especie de nivel superior, ya que se fundamenta no en un principio autónomo del filme sino en su posición como ente inscrito en un ambiente cultural que le otorga funciones y expectativas. En otras palabras, mientras que el modo grabar, revelar o preservar se sostiene en una propiedad de la imagen cinematográfica (la prestancia visual idéntica a la de su referente), el modo persuadir o promover comprende aquellos filmes que explotan el reclamo de veracidad constituido de forma histórica por esta misma característica primigenia. El valor de esta clase es absolutamente social debido a que es determinada por su relación con otros entes de la cultura.

El impulso persuasivo ha sido un tópico dominante en el sentido social que le confirió John Grierson. Ello ha generado un hábito de representación. Renov afirma que esta actitud ha encontrado espacio propicio para su desarrollo en el documental patrocinado por instancias estatales y pone los ejemplos puntuales de los casos de la Unión Soviética y Cuba (29). ${ }^{17}$ Asimismo reconoce que el rango de este modelo retórico es muy amplio el mismo ímpetu es reconocible en filmes como El triunfo de la voluntad de Leni Riefenstahl y la serie de Frank Capra Why we fight (Renov 30). A pesar de la variedad de técnicas y contenidos, en estas películas es reconocible la misma ansia de poner todos los recursos retóricos en función de un incontestable objetivo promocional.

La historia de las producciones del ICAIC y el peso extraordinario de su dimensión política convierten a esta modalidad como la tendencia movilizadora fundamental del documental cubano. Lloga y Silveira mantienen que el género desempeñó un papel relevante en proporcionar nuevos códigos de lectura del ambiente cultural cubano tras las radicales transformaciones de la estructura social de la Isla provocadas por la Revolución. Debido a la estrecha relación entre el instituto de cine y el Gobierno, es posible señalar que el documental colaboró en construir la visualización "oficial” del proceso revolucionario. La filmografía de Santiago Álvarez, con obras como Now!

17 A pesar de que este estudio coincide de forma general con los planteamientos de Renov, también considera que los filmes puntuales que presenta como prototipos no son del todo felices, al menos no sin una discusión previa. Como paradigma de filme promocional de la Unión Soviética, Renov menciona El hombre de la cámara (1929) de Dziga Vertov. Si bien el afán promocional primó en la cinematografía soviética de ficción producida en el mismo periodo (La huelga, El acorazado Potemkin, ambas de Sergei Eisenstein), también parece que los impulsos presentes de El hombre de la cámara no son del todo ajustables a estas ansias. Esta obra de Vertov es una propuesta mucho más compleja que asume como tema central la representación misma y la naturaleza de la percepción de realidad provista por un aparato mecánico. El tema de El hombre de la cámara es el cine mismo y la actitud que convoca en el exégeta es de sospecha e inquietud, una posición diametralmente opuesta a la idea de seguridad confortable sugerida por el filme del modo persuadir o promover. El error de Renov aquí, en mi opinión, es el de clasificar el mediascape del cine soviético de entonces y no reconocer la especificidad de cada filme en particular. 
(1965), Hanoi, martes 13 (1967), LBJ (1968) y 79 primaveras (1969), entre otras, se caracterizan por reproducir la proyección política internacional del poder estatal.

La modalidad analizar o interrogar responde a la tradición del documental de plantear sentencias "verídicas" sobre el mundo histórico. Esta categoría, al igual que la anterior, se construye en una dialéctica entre las propiedades ontológicas del filme y la ubicación que le es dada dentro del proyecto civilizatorio contemporáneo. Constituye, en cierta medida, una antítesis de la clase anterior. Reconociendo que el documental se halla en el campo de la información y asume como misión central la representación fiel de lo real, el tipo analizar o interrogar describe una de las aspiraciones que moviliza el género. La exploración y exposición de conclusiones acerca de la realidad colectiva es uno de sus usos más comunes de esta forma cinematográfica. Renov (30) lo presenta de la siguiente manera: "Análisis, en dicho contexto, puede ser considerado como el reflejo cerebral de la modalidad grabar/revelar/preservar; es su revelación interrogada”.

La concepción que Renov elabora sobre el análisis o la interrogación pasa por el sesgo de la reflexividad. Esto es, un texto audiovisual que escruta su propio estatus de propuesta mediática. Para este investigador, la reflexividad no significa que el filme deba incluir siempre un cuerpo de símbolos directamente relacionados con la realización fílmica de la obra (a la manera de Roger and me (1989), Bowling for Columbine (2002), y otros de Michael Moore), sino que la ruptura misma de la correlación entre imagen y sonido, o sea, la disrupción de un contexto de vericondicionalidad equivalente con el del mundo histórico (común en el cine de no-ficción), puede ser mecanismo efectivo para denotar la cualidad mediatizada del discurso documental. Para Renov, la explotación de tal método puede tener un impacto político relevante en la coyuntura política contemporánea.

Aun así, el modo analizar o interrogar identifica características generalizadas en la producción documental. Los filmes pertenecientes a este grupo asumen como línea narrativa la búsqueda y exposición de las causas de la situación real a la que se enfrenta. Esto quiere decir que todos los recursos que despliega, incluyendo la reflexividad, están en función de hallar un origen o principio responsable del evento que aborda. Aunque se hallan conectados en varios niveles, la película que analiza o interroga asume su premisa como un algo-desconocido que es necesario descubrir (a diferencia del modo persuadir o promover, que su tesis es un algo-conocido que es necesario demostrar y, luego, apoyar).

En el caso cubano, uno de los cineastas que con mayor ingenio desarrolló los recursos reflexivos fue Nicolás Guillén Landrián. En varios de sus documentales el contraste entre recursos provoca la inquietud de un discurso ambiguo que ancla el ser-ahí de la realización de la película en la coyuntura misma que recrea. Obras como Ociel del toa (1965) o Coffea arábiga (1968), si bien se sostienen en estéticas diferentes (un pausado tempo poético en uno; desenfreno, velocidad y exuberancia en otro), coinciden en que la aparente falta de armonía entre la imagen del mundo 
histórico, los intertítulos y la música no-diegética ofrecen un discurso donde la duda, la incomprensión y la interrogación se convierten en los móviles de las películas. ${ }^{18}$

Finalmente, Michael Renov plantea la modalidad expresar. Con ella pretende englobar aquellos filmes donde la voluntad estética adquiere una importancia más evidente. Se trata de encontrar un espacio teórico que siente las bases para una crítica de las obras con un trabajo formal no subordinado (o dependiente en menor medida) a la transmisión de información del mundo histórico. El modo pone atención a la contemplación como motivación central de la exégesis en lugar de la misión instrumental común en la representación documental. Se trata, en definitiva, de abordar la ubicación del filme de no-ficción que se posa en las fronteras difusas del mundo del arte.

Es importante señalar que el hecho de que se analice la estetización del cine documental corresponde a una necesidad epistemológica y no a una exigencia de corte humanista. Es decir, el esfuerzo teórico persigue identificar y valorar los recursos explotados por este tipo de filmes y que eventualmente han devenido herramientas comunes en el arsenal retórico del documental (de todo tipo de documental). Ya sea la conjugación emotiva de la música y la imagen, la composición de la imagen no con un fin expositivo sino pictórico, el uso infrecuente de la toma larga, etc., la inclinación al tropo del documental expresivo ha tenido un impacto mayúsculo como espacio de experimentación y constante ampliación del instrumental comunicativo del texto cinematográfico.

La producción documental con un fin expresivo ha estado presente a lo largo de la historia del cine desde su nacimiento y constituye una de sus ramas más célebres. Renov cita como ejemplos el lenguaje poético utilizado en Nanook of the North (1922, Robert Flaherty), el ciclo de sinfonías citadinas de finales de los años 20 -Berlín: sinfonía de una gran ciudad (1927), El hombre de la cámara (1929) y A propósito de Niza (1930)—, así como las primeras obras de Joris Ivens (Renov 33). Con ello, Renov demuestra que la motivación estética se halla en el núcleo de la tradición documental desde su nacimiento y señala igualmente la paradoja teórica de la desatención formalista con respecto a la no-ficción.

La disposición de Michael Renov se desentiende del discurso común de la historia del cine y enarbola sobre esa base una clasificación compuesta por clases que presentan fronteras sólidas. Ello es una victoria epistémica no solo porque permite alcanzar una representación del documental (que ya es en sí mismo representación del mundo histórico) con identidades y diferencias claras, sino, además, porque de esa manera se favorece su aplicación a otros ambientes cinematográficos cuyo desarrollo no es del todo coherente con la tradición mediática europea y norteamericana, sin dudas, el discurso mainstream del devenir de la historia del cine.

18 Un estudio ampliado de la reflexividad en la obra de Nicolás Guillén Landrián puede ser encontrado en el texto $L a$ mirada bajo asedio. El documental reflexivo cubano de Dean Luis Reyes. 


\section{El modelo de John Corner}

Corner es uno de los autores que ha propuesto un enfoque mucho más integral de la práctica documental, incluyendo en los análisis no solo la producción audiovisual sino además las teorías y estudios que alrededor de esta se generan. Esto da a su obra un aura de examen holístico con respecto al posicionamiento del documental a nivel social. Corner mantiene un diálogo fluido con el universo específico de los media studies, construyendo su teoría a partir de la especificidad científica provista por este campo. Esto marca una diferencia con respecto a los otros especialistas tomados en cuenta aquí (Nichols y Renov) quienes mantienen un eje teórico más amplio y difuso, incluyendo especialmente la estética y los cultural studies a sus exámenes.

La postura de John Corner se destaca por comprender el documental como una forma discursiva que atraviesa varias plataformas mediáticas adaptando sus retóricas y estéticas. Para este autor, la relación con el discurso de la televisión es central para el entendimiento no solo de las transformaciones experimentadas por el documental, sino que, en un sentido contrario, para el reconocimiento de la asimilación de expresiones documentales en productos televisivos de diversa índole. Asimismo, considera que es este uno de los móviles del conocido impulso de los documentary studies desde comienzos de los noventa ("Documentary Studies" 13). Si bien esta postura luce hoy como incontrovertible, Corner fue pionero en la identificación de estas manifestaciones. En una reseña sobre el libro de Nichols, Representing Reality publicada en 1993, Corner señala que:

Como un objeto exclusivamente cinematográfico (y mayoritariamente "cine independiente" también) el documental ciertamente nos presenta una rica variedad de "profundos" textos pero es en su articulación con los sistemas televisivos que es puesto ahora bajo las formas de presión más significativas (por ejemplo, el tener un buen valor de entretenimiento y operar dentro de reglas de imparcialidad) al mismo tiempo en que alcanza sus mayores consecuencias políticas ("Review on Bill Nichols" 416).

Luego, el reconocer la traza de la televisión en la estética documental contemporánea le permite a Corner plantear que es el documental interactivo el modo principal existente en Gran Bretaña y Norteamérica ("Review on Bill Nichols" 416). Ello reta la idea de Nichols acerca de la primacía del documental expositivo y confirma una realidad coincidente con el ambiente documental cubano posterior a la década de los noventa, momento en que la crisis económica de la Isla provocó el desplome de la producción cinematográfica del ICAIC y de su documental. El descentramiento sucedido entonces y la multiplicidad de agentes productores actuando en Cuba (Stock 2009) han construido desde entonces y hasta la actualidad un mediascape dinámico, heterogéneo, más cercano a los contextos globales.

La propuesta de clasificación de documentales realizada por Corner aspira a la exposición de las formas de descripción empleadas en el discurso documental. 
Su tipología se concentra en "identificar algunas de las vías principales en las que la comunicación es organizada en el documental" ("Documentary Studies" 27). El patrón se apoya en la división del uso de la imagen en cuatro formas diferentes y discurso hablado en tres. En el presente estudio se ha tomado en cuenta solamente la subdivisión concerniente a la imagen debido a que la segmentación del sonido puede ser comprendida en las primeras. Es una estructura abarcadora, es decir, se desentiende de discusiones cardinales como las cuestiones de definición del documental, las fronteras entre ficción y no-ficción o la especificidad del medio correspondiente (cinematográfico, televisivo, video-arte, etcétera).

Es importante considerar que esta es una clasificación que renuncia a la diacronía. La categorización de Corner luce particularmente adecuada para la exploración de ambientes audiovisuales periféricos porque examina el documental como un fenómeno transmediático, lo que resulta conveniente para entornos donde la circunstancia audiovisual está marcada por una profunda mixtura de tradiciones discursivas (estrictamente cinematográficas, o televisivas, o experimentales, o de video-creación) difíciles (¿imposibles?) de deslindar.

Los cuatro modos son evidencial 1 (observacionalismo reactivo), evidencial 2 (observacionalismo proactivo), evidencial 3 (ilustrativo) y asociativo. Resulta notorio como tres de las cuatro clases corresponden a formas de evidencialidad. De esta manera, Corner refuerza la idea de la veracidad (o el reclamo de veracidad) como fundamento de la retórica documental. La diferencia entre las categorías evidenciales, por tanto, corresponden a las distinciones retóricas empleadas por el documental en la exposición de ese reclamo de veracidad.

El modo evidencial 1 (observacionalismo reactivo) describe el empleo del filme como registro del mundo histórico basado en la intervención mínima. Lo filmado, concebido como inscripción de sucesos "reales", constituye el material primario no solo para las formas documentales del cine directo, sino que asocia el mismo impulso, con especial fuerza, a los discursos televisivos comprometidos con el acontecer de la vida real. Reproduce la capacidad de testigo de situaciones relevantes acontecidas en el mundo histórico de las que el filme resulta memoria gráfica. Este modo pone atención a un deseo de inmediatez de las películas y limita en lo posible la inevitabilidad de la mediación del contenido filmado. De acuerdo con Sharon Lin Tay (82), esta controversia atraviesa gran parte de las problemáticas asumidas por los documentary studies.

El modo es equivalente a la función de grabar, revelar o preservar de la tipología de Renov. La cinematografía documental del ICAIC no ofrece una tradición fuerte en esta modalidad más allá de sus expresiones en el Noticiero, como fue planteado anteriormente. No obstante, debido a la posición central del ejercicio de registro dentro de la ontología del género, la observación reactiva está presente en varios filmes, especialmente en aquellos realizados en los primeros años posteriores a la fundación del ICAIC . Tomás Gutiérrez Alea ofrece dos motivos para la preeminencia de este modo en los albores de la gestión documental del instituto. En primer lugar, la violencia 
irruptora de los cambios sociales hacía sumamente atractivos los eventos recogidos y, en segundo lugar, los realizadores de ese momento tenían muy poca experiencia en la realización cinematográfica y "aprenden a hacer cine sobre la marcha [...] y logran interesar al espectador más por lo que muestran que por cómo lo hacen” (Gutiérrez Alea 20). Películas como Sexto aniversario (1959, Julio García Espinosa) o Asamblea general (1960, Tomás Gutiérrez Alea) son ejemplos de ello. La manipulación explícita de la realidad constituye una "experiencia del hacer" celebrada en el cine cubano.

Una obra notable al respecto es Ciclón (1963), de Santiago Álvarez. Se trata de una película que recoge los destrozos sucedidos en la región oriental de la Isla luego del azote del huracán Flora, en octubre de 1963, así como las gestiones del Gobierno y sus figuras políticas principales en la atención al pueblo. Pero no solo en el plano del contenido Ciclón (1963) es una pieza notable. En las secuencias iniciales se observan varias escenas de procesos productivos de la industria y la agricultura. Estas son presentadas en montaje paralelo y con una música no-diegética de tempo optimista. Cada uno de los segmentos vistos es detenido de improviso y la imagen se congela en la pantalla. La interrupción brusca de lo observado marca el fin de la parte introductoria del filme, a partir de entonces, continúa con los acontecimientos del huracán. El efecto de paralización provoca un sobresalto en el espectador: simula un desperfecto de la exhibición, como si el proyector se hubiese estropeado súbitamente. Es un recurso reflexivo de gran impacto, que muestra que ni siquiera en las obras donde la premisa depende mayoritariamente del suceso profílmico sucedido a priori, los realizadores renuncian de su condición de creadores activos del texto audiovisual.

La reafirmación de la presencia creativa sobre la base de estos recursos sugiere una relación con la audiencia donde la simulación/sustitución de una realidad no es el eje fundamental del documental, tal y como plantean varios investigadores (Aitken 1). En cambio, es síntoma de una experiencia de exégesis donde la audiencia es consciente de la condición de representación del ejercicio documental, por lo que el género no pretende ser sustituto de una realidad. Ello es más cercano a la idea de Stella Bruzzi (7) de que "el significado del documental no es fijo sino fluido y proviene de una productiva relación dialéctica entre el texto, la realidad que representa y el espectador".

La clasificación de John Corner propone además el modo evidencial 2 (observacionalismo proactivo). Aquí, aunque el discurso continúa fundamentándose en la descripción visual del mundo histórico, se valora una mayor intervención por parte de los realizadores. Es decir, el filme exhibe formas más evidentes de su mediación (interpretación/expresión de eventos) en un ambiente "más densamente codificado" (The Art of Record 28). Corner propone que un uso más tangible de la mise-en-scène es la clave de identificación del modo y el rango puede ir desde una organización de los espacios hasta - el caso extremo- las dramatizaciones. Esta categoría presenta una heterogeneidad de manifestaciones y la fusión de múltiples recursos retóricos.

El observacionalismo proactivo es más común que la variante reactiva. Es una forma híbrida que se define por negación, o sea, porque no es la no-intervención lo 
que la identifica y porque el dominante narrativo parece mantener una equivalencia entre el discurso visual y el discurso sonoro. La revisión de la historia del documental del icAic halla en este modo la regularidad de sus propuestas de representación. Como categoría, el observacionalismo proactivo es corto a la hora de explicar las múltiples facetas en las que la intervención de los realizadores puede ser apreciada o puntualizada en técnicas específicas. El arco bajo el concepto ocupa desde variantes participativas, como el documental de entrevista que se hizo popular en los años ochenta ${ }^{19}$ o la presentación de grupos de discusión, ${ }^{20}$ hasta las formas más sutiles o poéticas de performatividad (como en Wifredo Lam, 1979, de Humberto Solás).

El modo evidencial 3 (ilustrativo) es descrito como la subordinación del discurso visual al discurso hablado, el cual sostiene la narrativa de la película. De acuerdo con Corner, esta forma es muy común en la retórica de las noticias. Se caracteriza por una debilidad visual en el proceso de la conducción narrativa, por los bajos niveles de continuidad y por un poco esfuerzo en el valor de duración del observacionalismo (The Art of Record 29). En este modo, todo lo visto actúa como instancia probatoria de todo lo escuchado.

En las películas agrupadas bajo esta modalidad la conducción verbal escuchada puede manifestarse a través de dos vías fundamentalmente: por lo pronto, es posible encontrar un narrador (que a su vez puede ser en offo puede manifestarse como parte de la escena, como en las noticias) quien conduce, explica o expone todo el contenido del filme mientras que las instancias visuales recrean o demuestran aquello de lo que se habla. Por lo demás, la otra forma común es el testimonio, donde la entrevista o la exposición de ideas a partir de un intercambio ante la cámara constituyen el eje narrativo de la obra. En ambas opciones es clara la primacía de una forma discursiva con respecto a otra.

Resulta importante reconocer que no siempre que aparezca una voz en off en actitud de narrador resulta axiomática la clasificación del filme como una película de modo ilustrativo. El filme etnográfico es ejemplar en este sentido. Mientras en un nivel visual son las formas observacionales las que priman, resulta habitual (y casi obligatorio de acuerdo con la opinión de algunos especialistas como Jay Ruby) la presencia en off de un narrador. En la mayoría de las ocasiones, sin la intervención del mismo, el contenido del filme permanece ilegible.

En esta circunstancia es complejo identificar la primacía de algún elemento, puesto que ambos son esenciales en la comprensión. Sin embargo, para el documental etnográfico es la forma visual lo que marca la guía de los eventos presentados y el discurso hablado sigue lo visto como refuerzo de su significación. Aquí es lo visual el elemento fundamental, es la marca distintiva que marca su justificación ontológica.

19 Ver Yo también te haré llorar (1984) y Vecinos (1985) de Enrique Colina. 20 Ver Hablando del punto cubano (1973) de Octavio Cortázar. 
Es el ver, el mostrar, lo más importante en el documental etnográfico. Por ello no es posible la denominación axiomática de cualquier filme como modo ilustrativo solo por la presencia de un narrador o de un testimonio. Una vez más, es el mecanismo dominante en la demostración de la premisa lo que actúa como unidad definitoria.

Corner reconoce finalmente una cuarta modalidad documental, el modo asociativo. Con esta se describe una forma particular de empleo de recursos audiovisuales los cuales son dispuestos con el objetivo de lograr significaciones, no sobre la información transmitida a través de cada uno de esos elementos, sino a partir de las combinaciones expuestas en el filme.

De esta manera, el autor reconoce una actitud estetizada en la prestancia del filme asociativo. Se expresa así la voluntad del filme de construir sus consideraciones por la yuxtaposición de sus componentes y obtiene un resultado de mayor complejidad simbólica. Las esencias de esta modalidad parecen hallar pretexto en las teorías del montaje intelectual propuestas por Eisenstein. La comprensión de la obra descansa, entonces, en la coherencia de la sintaxis de sus componentes. Por ello el filme asociativo parece oponerse diametralmente al observacionalismo reactivo. Si en el segundo el desarrollo de los acontecimientos del mundo histórico dictaba la evolución de la trama del filme, en el primero, por otro lado, la actitud proactiva es llevada a su extremo al asumir lo contado como una manufactura de recursos cuya disposición determina su trascendencia. Aunque Corner declara la existencia del modo asociativo también en formas retóricas más enfocadas en lo referencial, como el reportaje noticioso, reconoce asimismo que el mayor uso de esta modalidad es estético en lugar de cognitivo. De ahí que demande del espectador una exégesis de la obra diferente a otras retóricas más atadas a la información.

Es esta la actitud estética que determinó en gran medida la filosofía detrás del cine documental cubano producido por el ICAIC en los años sesenta. Profundamente influidos por los presupuestos teóricos de la vanguardia soviética, cineastas cubanos como Santiago Álvarez o Nicolás Guillén Landrián (en los documentales posteriores a 1966) asumieron la modalidad asociativa como mecanismo rector de su discurso. Si bien no fue esta la modalidad dominante en aquella etapa, su uso generó varios de los filmes más célebres de entonces. ${ }^{21}$ Un tópico interesante de esta coexistencia es que se sucedió en espacios supuestamente comprometidos con una metódica informativa, como el Noticiero ICAIC Latinoamericano. En su lugar, la estetización de la película documental no fue nunca asumida como una problemática sino como una necesidad

21 La documentalística del ICAIC en los sesenta se muestra particularmente rica. Si en los primeros años siguientes al surgimiento de la industria cubana de cine en 1959 el neorrealismo fungió como paradigma estético, pronto fue evidente que los cineastas cubanos explorarían otras muchas retóricas. Así, también se hacen presente formas observacionales reactivas y, mayormente, proactivas, y también, hacia finales de la década, el documental ilustrativo comienza a hacerse popular a partir la obra de Sara Gómez. Películas como Now! (1965) y LBJ (1968) de Santiago Álvarez, Coffea Arábiga (1968) y Desde La Habana, 1969, ;recordar! (1972) de Nicolás Guillén Landrián son paradigmas de la cinematografía latinoamericana y exponentes representativos de la modalidad asociativa. 
de la transmisión mediática de los contenidos. En décadas posteriores, aunque la presencia del filme asociativo se reduce considerablemente dentro de la producción del ICAIC, otros cineastas fungieron como continuadores de esta retórica. ${ }^{22}$ Aún hoy, esta modalidad es celebrada por el ICAIC.

\section{Conclusiones}

En este artículo se realizó un análisis de las modalidades del documental elaboradas por tres importantes académicos del cine: Bill Nichols, Michael Renov y John Corner. De igual forma, ilustró las categorías con prácticas concretas extraídas de la documentalística producida por el ICAIC entre 1959 y 1991. Es una nueva visión que especular acerca de un devenir posible del cine cubano visto más allá de su contexto teórico como cinematografía nacional, estrechamente atada a condicionantes políticas y económicas. Aplicar los modos a la experiencia de Cuba refuerza la atención hacia el componente estético de los filmes.

Los tres modelos estudiados aquí ofrecen clasificaciones basadas en fundamentos teóricos diferentes. Las categorías que componen cada sistema no son dadas al exégeta a partir de la simple percepción del filme, sino que resultan construcciones culturales definidas históricamente. Cada patrón provee un sistema de semejanzas y diferencias que hace surgir de ellas un orden, una estructura. La variedad en su episteme permite examinar el documental de una forma compleja.

Los esquemas comportan una manera de comprender el documental. Aunque tienen una misión epistémica similar, los objetivos, métodos de análisis y conclusiones a las que arriban son divergentes. Aplicar solo una clasificación encierra también la adscripción a tal entendimiento del género. Ello puede resultar útil en la interpretación individual de las obras, pero ante las interpretaciones de vastos conjuntos de filmes, una sola modalidad limita la descripción de las posibilidades que el filme presenta. Por tanto, valerse de una clasificación múltiple como la propuesta aquí permite discutir tanto de la obra en cuestión como de las posturas teóricas que circulan alrededor de las interpretaciones del mismo. Es necesario acentuar en la riqueza que aporta la combinación de información provista en estas sistematizaciones. La búsqueda de los puntos de contacto entre ellas en cada filme reconoce la existencia del documental como parte no de una única historia y evolución, sino su naturaleza heterogénea y multidimensional.

La trama ofrecida por las tres clasificaciones permite reconocer la riqueza del documental producido por el ICAIC. Ofrece recursos metodológicos para diseccionar este gran corpus en conjuntos específicos de técnicas, motivaciones, funciones y 
efectos. La aplicación de los modos de representación favorece la valoración de los filmes, no ya desde sus temáticas y contenidos, sino desde su vasto arsenal de recursos retóricos. La disquisición sobre los modos acentúa la dimensión estética de las obras y contribuye a la revelación de personalidades autorales y tendencias epocales. La teoría de cine documental aporta nuevas herramientas para la profundización del documental cubano del ICAIC, una de las experiencias de no-ficción más coherentes del cine latinoamericano.

\section{Referencias}

Aitken, Ian, editor. The Concise Routledge Encyclopedia of the Documentary Film. Nueva York, Routledge, 2013.

Almendros, Néstor. "Pasado Meridiano". En El caso PM: Cine, poder y censura. Eds. Orlando Jiménez y Manuel Zayas. Madrid, Colibrí, 2012, pp. 11-12.

Aufderheide, Patricia. Documentary Film. A Very Short Introduction. Oxford, Oxford University Press, 2007.

Barbash, Ilisa y Lucien Taylor. Cross-cultural Filmmaking. A Handbook for Making Ethnographic Films and Videos. Los Ángeles, University of California Press, 1997. Beattie, Keith. Documentary Screens. Non-fiction Film and Television. Nueva York, Palgrave Macmillan, 2004.

Bordwell, David. "Contemporary Film Studies and the Vissicitudes of Grand Theory." En Post-theory. Reconstructing Film Studies. Eds. David Bordwell y Noël Carroll. Madison, University of Wisconsin, 2006, pp. 3-36.

-_. Poetics of Cinema. Nueva York, Routledge, 2008.

Bruzzi, Stella. New Documentary $2^{\text {nd }}$ Edition. Nueva York, Routledge, 2006.

Carroll, Nöel. Theorizing the Moving Image. Cambridge, Cambridge University Press, 1996.

Chanan. Michael. Cuban Cinema. Mineápolis, University of Minnesota Press, 2004. Clifford, James y George Marcus, editores. Writing Culture. The Poetics and Politics of Ethnography. Berkeley-Los Ángeles, University of California Press, 1986.

Corner, John. "Review on Bill Nichols, Representing Reality: Issues and Concepts in Documentary”. Screen, vol. 34, n. ${ }^{\circ}$ 4, 1993, pp. 414-417.

- - The Art of Record: A Critical Introduction to Documentary. Manchester, Manchester University Press, 1996.

- - "Documentary Studies. Dimensions of Transition and Continuity." En Rethinking Documentary. New Perspectives New Practices. Eds. Thomas Austin y Wilma de Jong. Nueva York, Open Univesity Pres, 2008, pp. 13-28.

Del Rincón, María. “Una comparación de las teorías del cine documental de Bill Nichols y Carl Plantinga: fundamentos, definiciones y categorizaciones”. Cine Documental, n. ${ }^{\circ} 1,2015$, pp. 29-51. 
"Discusiones de los intelectuales y el poder: Fragmentos de las grabaciones originales de las discusiones sostenidas entre Fidel Castro, dirigentes del gobierno revolucionario y los intelectuales cubanos, en junio de 1961 en la Biblioteca Nacional de La Habana”. El caso PM: Cine, poder y censura. Eds. Orlando Jiménez y Manuel Zayas. Madrid, Colibrí, 2012, pp. 163-186.

Derrida, Jacques. Archive Fever. A Freudian Impression. Chicago, The University of Chicago Press, 1996.

García Borrero, Juan Antonio. "Sara Gómez." Cine documental en América Latina. Ed. Paulo Antonio Paranaguá. Madrid, Cátedra, 2003, pp. 179-186.

Gutiérrez Alea, Tomás. Dialéctica del espectador. La Habana, eictv, 2009.

Jiménez, Orlando y Manuel Zayas, editores. El caso PM. Cine, poder y censura. Madrid, Editorial Colibrí, 2012.

Jiménez, Orlando y Manuel Zayas. "Un baile de fantasmas”. El caso PM: Cine, poder y censura. Eds. Orlando Jiménez y Manuel Zayas. Madrid, Colibrí, 2012, pp. 142-161.

Lin Tay, Sharon. "Undisclosed Recipients: Documentary in an Era of Digital Convergence." Studies in Documentary Film, vol. 2, n. ${ }^{\circ}, 2008$, pp. 82-88.

Lloga, Carlos y David Silveira. "Perspectivas de consenso y conflicto en el documental cubano de los sesenta. La hermenéutica ontológica como estrategia de interpretación de la realidad." Santiago, n. ${ }^{\circ}$ 145, 2018, pp. 101-118.

Metz, Christian. "La enunciación personal o el lugar del filme." Semiosis, n. ${ }^{\text {30-31, }}$ 1993, pp. 53-80.

Nichols, Bill. Representing Reality. Issues and Concepts in Documentary. BloomingtonIndianápolis, Indiana University Press, 1991.

- - L L representación de la realidad. Cuestiones y conceptos sobre el documental. Barcelona, Paidós, 1997.

- - Introduction to Documentary $1^{\text {st }}$ Ed. Bloomington, Indiana University Press, 2001.

- - Introduction to Documentary $2^{\text {nd }} \mathrm{Ed}$. Bloomington, Indiana University Press, 2010.

Plantinga, Carl. Rhetoric and Representation in Non-fiction Film. Cambridge, Cambridge University Press, 1997.

Pogolotti, Graziella, editora. Polémicas culturales de los sesenta. La Habana, Letras Cubanas, 2007.

Renov, Michael. “Towards a Poetics of Documentary Film.” Theorizing Documentary. Ed. Michael Renov. Nueva York, Routledge, 1993, pp. 12-35.

Reyes, Dean Luis. La mirada bajo asedio: El documental reflexivo cubano. Santiago de Cuba, Ediciones Oriente, 2010.

Ruby, Jay. Picturing Culture: Explorations of Film y Anthropology. Chicago, University of Chicago Press, 2000.

Sánchez, Jorge Luis. Romper la tensión del arco: Movimiento Cubano de Cine Documental. La Habana, Ediciones ICAIC, 2010.

Soberón, Edgar, editor. 33 Ensayos sobre cine. La Habana, EICTV, 2008. 
Stock, Ann Marie. On Location in Cuba: Street Filmmaking during Times of Transition. Carolina del Norte, University of North Carolina Press, 2009.

Tamayo, María del Carmen. "Otra mirada al cine cubano: Crítica social, humor y sinergia en el documental del ICAIC de 1979-1991". Tesis para optar al grado de Licenciado en Historia del Arte, Universidad de Oriente, 2017.

Enviado: 5 de octubre de 2018

Aceptado: 13 de marzo de 2019 